\title{
Vertientes y acequias: explotación de los recursos hídricos y el sistema de riego en el valle de Azapa en tiempos prehispánicos
}

\author{
Slopes and streams: utilization of water resources and irrigation \\ system in Azapa Valley in prehispanic times \\ Iván Muñoz ${ }^{*}$, José Rocha ${ }^{1}$
}

\section{RESUMEN}

El reconocimiento de nuevas vertientes u ojos de agua en el valle de Azapa, sector Quebrada del Diablo-San Lorenzo, nos ha permitido tener evidencias de antiguos acuíferos, recursos hídricos que usaron las poblaciones prehispánicas asentadas en el poblado de San Lorenzo AZ-11, entre el 700 d.C. y el 1000 d.C., para regar sus plantaciones de maíz, porotos, ají, camote, calabazas, entre otros cultivos. Esas aguas habrían sido conducidas a través de acequias, las cuales proporcionaron líquido permanente para el riego en una época en que el río San José no escurría por el cauce. Este sistema de riego habría permitido un desarrollo de las prácticas agrícolas en forma permanente, lo que les habría generado excedentes de producción, recurso fundamental para el intercambio con poblaciones de otras regiones andinas.

Palabras clave: vertientes, acequias, recursos hídricos.

\begin{abstract}
The exploration of new slopes or water eyes in Azapa Valley, Diablo-San Lorenzo gully area, allowed us to have evidence of ancient aquifers, water resources used by the prehispanic populations settled in San Lorenzo village (AZ-11), between 700 AC to 1000 $A C$, to irrigate their corn, beans, pepper, sweet potato and pumpkin plantations among others. These waters would have been run through streams, which provided permanent liquid for irrigation when San José river did not flow in the riverbed. This irrigation system would have allowed the development of agricultural practices permanently and it may have led to having production surplus, a critical resource for the interchange with populations of other Andean regions.
\end{abstract}

Keywords: slopes, streams, water resources.

\section{Introducción}

La domesticación de plantas en los Andes fue un proceso gradual que se realizó a través de muchos milenios, y que estuvo íntimamente relacionado con la disponibilidad de los recursos hídricos, suelos ricos en nutrientes y plantas propias de ecosistemas húmedos, las cuales fueron utilizadas por las poblaciones como medios de subsistencia. Desde la perspectiva económica, la agricultura fue un proceso que dio mayor estabilidad y seguridad a la vida de las sociedades cazadoras y recolectoras afianzando el sedentarismo. Además facilitó el crecimiento de la población y propició el desarrollo de una vida aldeana a través de una serie de culturas que junto con la agricultura habrían plasmado su historia cultural.

En cuanto a los inicios de la agricultura en los valles de Arica, como fue el caso del valle de Azapa, esta actividad fue posible gracias a una larga experimentación de cultivos de plantas y a la organización de las poblaciones que participaron en el proceso a través del tiempo. Ambos factores contribuyeron a obtener los mejores resultados mediante la producción de recursos que proveyó la tierra azapeña (Muñoz, 2004). Los primeros asentamientos en este valle fueron establecidos por pequeños grupos de pescadores que se movilizaban por la zona para desarrollar las prácticas agrícolas. Estos grupos probablemente se desplazaban

\footnotetext{
$1 \quad$ Universidad de Tarapacá, Departamento de Antropología. Arica. Chile.

* Autor para correspondencia: imunoz@uta.cl
} 
en períodos cortos a los lugares de cultivos, y regresaban a los campamentos bases que se encontraban cerca del litoral.

Como consecuencia del conocimiento del entorno, los agricultores escogieron el sector medio del valle de Azapa ( $\mathrm{km} 5$ al 18) porque constituía el mayor espacio para cultivar y construir los asentamientos humanos. Este sector se ubica en un ambiente de clima desértico, con neblinas abundantes que no se transforman en precipitaciones. No obstante, esta humedad permitió según Greisal (1974), el crecimiento de una gran variedad de flora silvestre como grama (Triticum espín L), chilcas (Baccharis petriolata y Baccharis marginalis), caña común (Arundo donax L), yerba del platero (Equisetum sp), guillave (eulychnis spinibargis), totora (Typha angustifolia $L$ ) Chépica (Aspalum vaginatum) sauce amargo (Salix nigra) molle (Lithrea molle Gay), algodón (Gossipium indicum), pimiento (Schinus molle) y chañar (Geofroea decorticans). Esta vegetación natural constituyó un recurso importante durante el proceso de sedentarización proporcionando nutrientes básicos para la alimentación de los pescadores, a través de moliendas para preparar harinas. Además se utilizó para confeccionar vestimentas, esteras funerarias y material constructivo para viviendas, entre otros usos. Ahora bien, al analizar este sector del valle nos preguntamos: ¿Por qué se eligió este espacio del valle para hacer las primeras experimentaciones agrícolas? Pensamos que la respuesta(s) habría que buscarla a través de los siguientes factores ecológicos y culturales:

a) La existencia en este sector del valle de recursos hídricos permanentes mediante afloramientos de aguas subterráneas. Estas vertientes y ciénagas de donde emergió agua dulce de buena calidad para el riego de frutales y hortalizas, se hallan delimitadas tanto al oeste como al este por dos quebradas secas, El Diablo y Las Llosyas, tributarias del río San José, las que al confluir al valle principal con sus sedimentos, obstaculizan el escurrimiento subterráneo de aguas, provenientes de la cordillera, las cuales se ven obligadas a aflorar a través de vertientes. Sin embargo, estas características fueron propicias solo en el cajón del valle, ya que los interfluvios no presentan condiciones óptimas para desarrollar la agricultura. b) La presencia de estos recursos de agua habría permitido un ecosistema vegetacional, que atrajo animales para la caza mayor y menor como guanacos (Lama guanicoe), vizcachas (Lagidium viscociacuviere) y chinchilla (Chinchilla chilensis), lo cual habría ayudado a la obtención de carnes rojas. Otros animales que se habrían sumado a esta cadena conformada a partir de esos sistemas acuosos fueron las aves de ambientes de altura, como flamencos, garzas y variedades de patos, que emigran especialmente en invierno de los climas lluviosos de la cordillera andina hacia la costa. La llegada temporal de estas especies habría permitido que aumentaran localmente los recursos de caza terrestre.

c) Como consecuencia del conocimiento del medio, los agricultores escogieron este lugar del valle porque constituiría el mayor espacio para cultivar. Allí las tierras agrícolas formadas esencialmente por terrazas fluviales alcanzan una extensión de ladera a ladera de 800 a 1.000 $\mathrm{m}$, lo cual les habría permitido utilizar el riego por acequia.

En relación con los suelos, Tapia (2014) señala que el material que conforma el piso del valle está constituido por la deposición de materiales sedimentarios con una marcada estratificación, producidos por el reacondicionamiento y sedimentación aluvial. En general, se trata de suelos formados a partir de sedimentos aluviales mixtos, poco evolucionados, que van desde aquellos relativamente delgados, textura gruesa y permeabilidad rápida, como es el caso de los ubicados en el sector alto del valle, hasta aquellos profundos, de textura fina a moderadamente gruesa y con un buen drenaje, propios de los sectores del curso bajo. La condición de alta permeabilidad que caracteriza al lecho del río facilitó la intensa infiltración de las aguas hacia las napas subterráneas, haciendo desaparecer el débil flujo superficial. Sin embargo estas, en su desplazamiento subsuperficial hacia el nivel de base oceánico, presentaban varios afloramientos en la parte baja del valle, en especial en dos sectores: Las Riberas y Las Ánimas. En ambas zonas, la confluencia con el río principal de las quebradas El Diablo y Las Llosyas, respectivamente, ha aportado materiales finos que interrumpen el flujo del acuífero, originando un conjunto de vertientes. 


\section{Las aguas de vertientes}

El sistema hidrográfico del río San José presenta condiciones propias de escurrimiento intermitente puesto que, normalmente, el flujo de agua superficial de su caudal natural no alcanza el nivel de base oceánico, aun cuando en su curso superior y afluentes, como el río Tignamar y quebradas menores, tiene un caudal permanente pero débil (Tapia, 2014). Estas características han favorecido, tanto en el presente como en el pasado, la existencia de una actividad agrícola de pequeña escala en áreas intramontañas de la sierra o precordillera ariqueña, lo que ha posibilitado el asentamiento permanente de poblaciones en ese piso ecológico.

Las vertientes del valle de Azapa constituyeron la fuente principal de recursos hídricos utilizada por los agricultores prehispánicos para regar sus cultivos a través de un sistema de canalización de las aguas. El área geológica que permitió la existencia de mayor número de vertientes se encuentra desde la quebrada. El Diablo por el oriente hasta la quebrada de Las Llosyas por el poniente. En este conjunto de vertientes es posible distinguir dos grupos. El primero está ubicado en el sector Las Riberas y es generadoocasionado por una cierta interrupción del acuífero provocada por los acarreos más finos de la quebrada El Diablo. El segundo grupo se encuentra en la zona de Las Ánimas, específicamente en los sectores Las Maitas y Juan Noé, y es originado por una acción semejante debido a los acarreos de la quebrada Las Llosyas. Los caudales de todas estas vertientes provienen del acuífero subterráneo y al no haber precipitaciones en la zona cercana a la costa, dependen de las del sector alto de la hoya del rio San José.

Las referencias bibliográficas en torno al abastecimiento de agua de riego en el valle de Azapa señalan que hasta la década de los sesenta correspondía a aguas subterráneas. En consecuencia, el aporte de las aguas superficiales sólo ocurría cuando se producían las "bajadas" del río San José. Los pobladores aprovechaban la oportunidad de cultivar productos de temporada por espacios de tiempo limitados. Crom (1991) señala que hasta inicios de la década de los 60 el escurrimiento natural del río se caracterizó por su gran variabilidad. Por su parte, Keller (1946) destaca que la condición agrícola del valle de Azapa, hasta mediados del siglo XX, estaba sustentada por el aporte de las vertientes y el cultivo en paños de tierras aisladas. Así lo señalan documentos del período colonial, como es el caso de la descripción que hace Fray Antonio Vázquez de Espinosa a partir de la visita realizada en 1618 .

Respecto a las aguas subterráneas, estas provenían de numerosos afloramientos naturales, ubicados cerca del río, que permitían llevar a cabo una agricultura de regadío en las áreas aledañas. Esta situación explica la concentración de cultivos en los suelos de la parte baja del valle de Azapa antes del trasvase de aguas altiplánicas. Los sectores superiores del valle permanecieron sin cultivos hasta que se produjo el aumento en el caudal de las aguas. Ese fenómeno inició un fuerte proceso de intensificación agrícola, pasando de 800 a 3500 ha (INGENDESA, 2003).

\section{Reconocimiento y captación de aguas por vertientes entre el sector Quebrada del Diablo-San Lorenzo, valle de Azapa}

El reconocimiento de los antiguos acuíferos, sector Quebrada del Diablo y San Lorenzo, se logró mediante la interpretación de documentación cartográfica, imagen satelital y los datos de geo-referencia espacial de los acuíferos, además de la información proporcionada por antiguos residentes del valle: Valdemar Antonio Huanca, José Linares y Ricardo Mendoza (Figura 1). El objetivo de este reconocimiento es conocer de dónde habrían obtenido el agua de riego para sus plantaciones las poblaciones de San Lorenzo, el mayor asentamiento humano en la época prehispana en el valle de Azapa.

De la información proporcionada por los informantes se verificaron y contabilizaron en terreno 14 conductos/oquedades naturales concentrados y avecindados en las riberas norte y sur del río San José. El recorrido guiado se inició en el afluente denominado El Quinto para posteriormente visitar Hornito, Conchalique, Pejerrey, El Indio Muerto, Matavaca, Las Ánimas, San Miguel, La Noria 1 y 2 y finalmente El Estanque. Los casos de El Socavón, La Concepción, Peña Blanca y La Peña poseen registros institucionales con antelación a esta prospección (Figuras 2 al 12). En la actualidad, La Concepción (parcela familia Silva) y El Socavón (parcela familia Madrid) corresponden a los dos únicos brotes hídricos naturales que registran existencia concreta en 


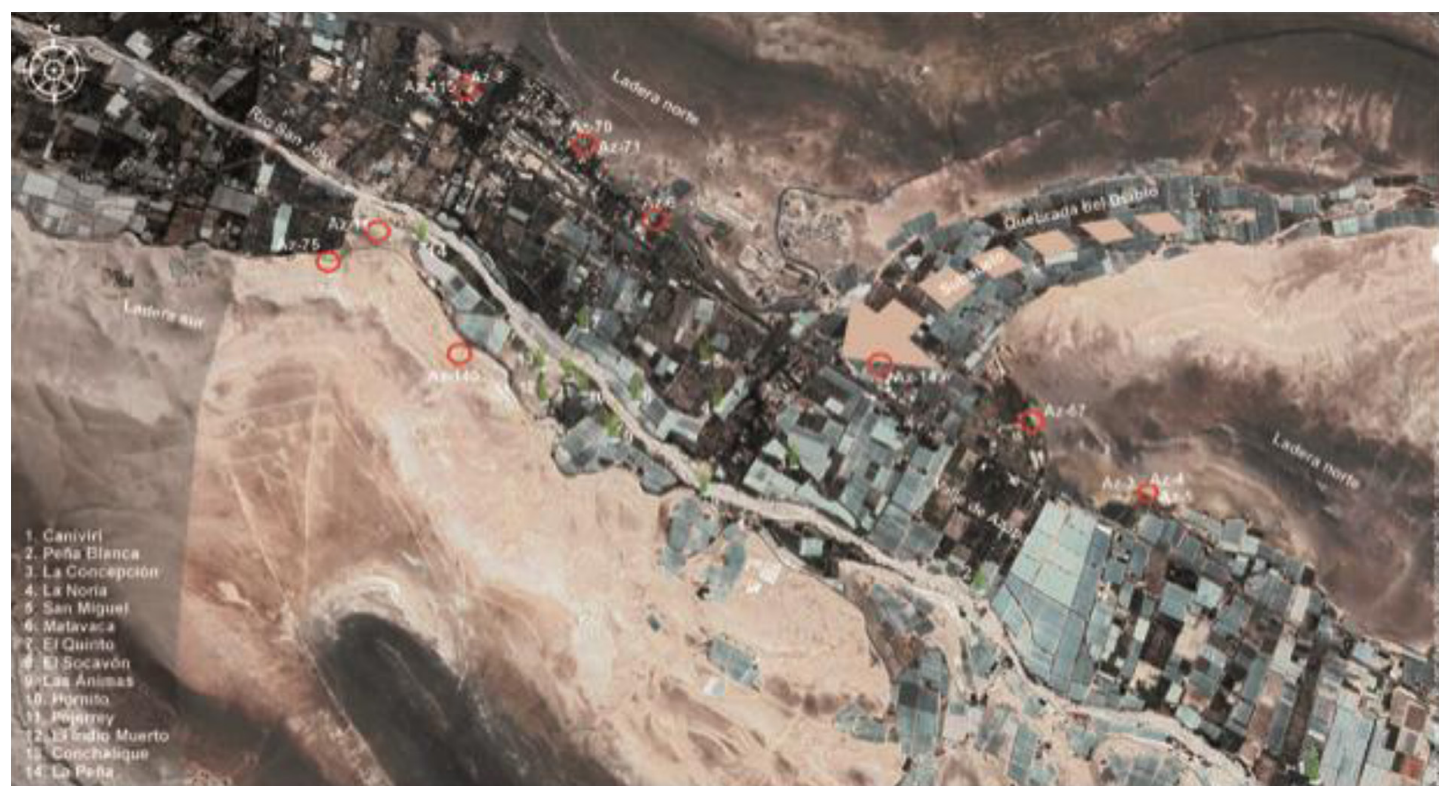

Figura 1. Dinámica geológica entre Quebrada del Diablo y Valle de Azapa para origen, distribución espacial de manantiales y asentamientos humanos prehispánicos.
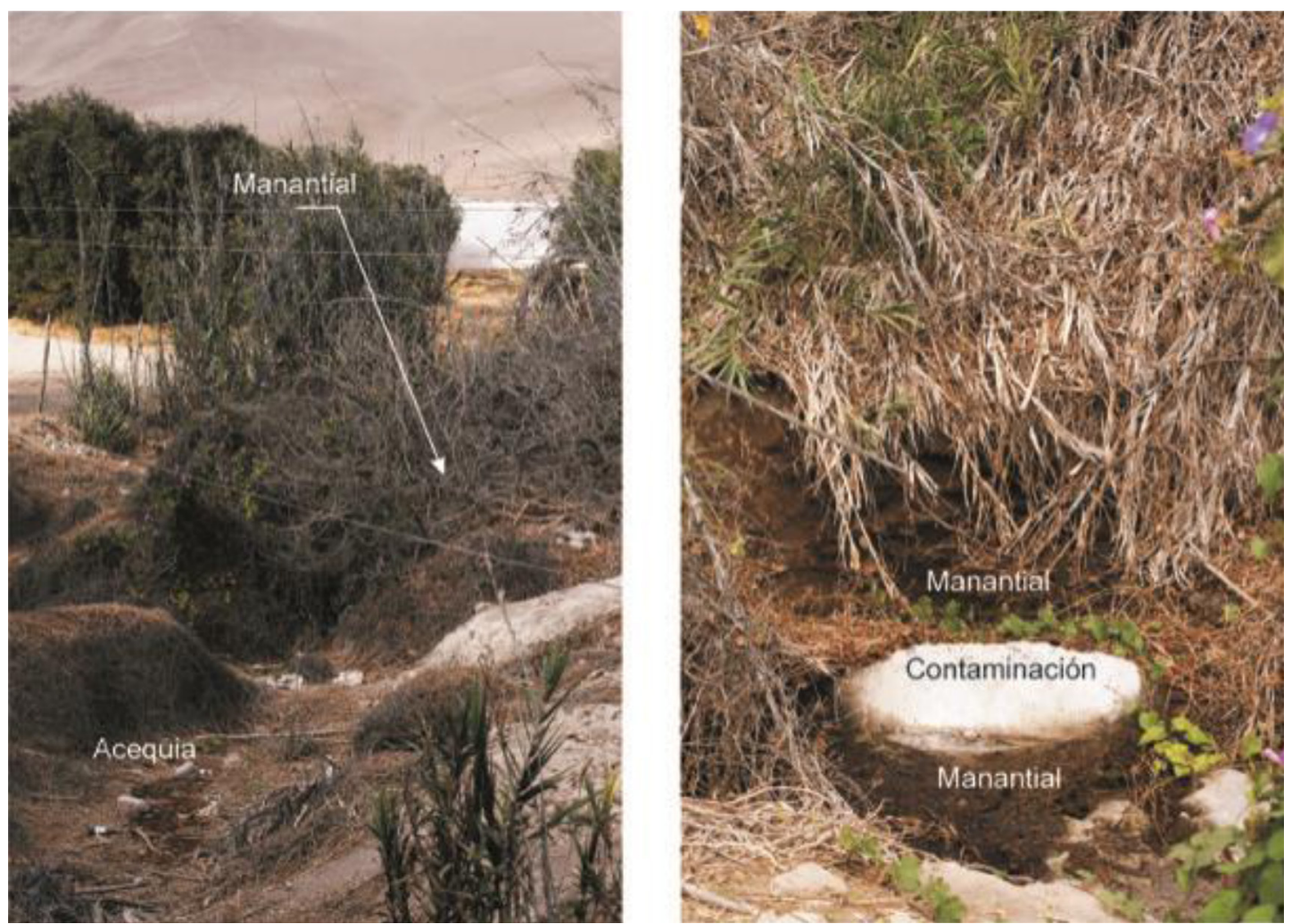

Figura 2. Manantial La concepción (izquierda). Manantial familia Silva (derecha). 

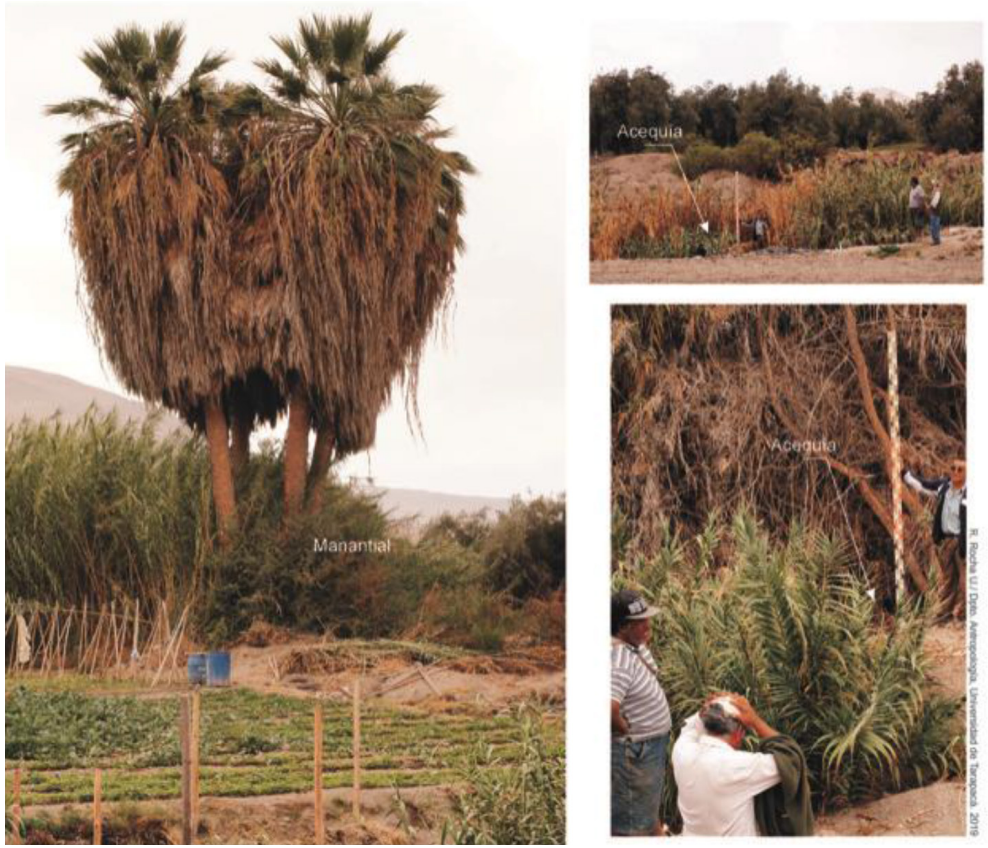

Figura 3. Manantial La Noria, asociada a acequias.
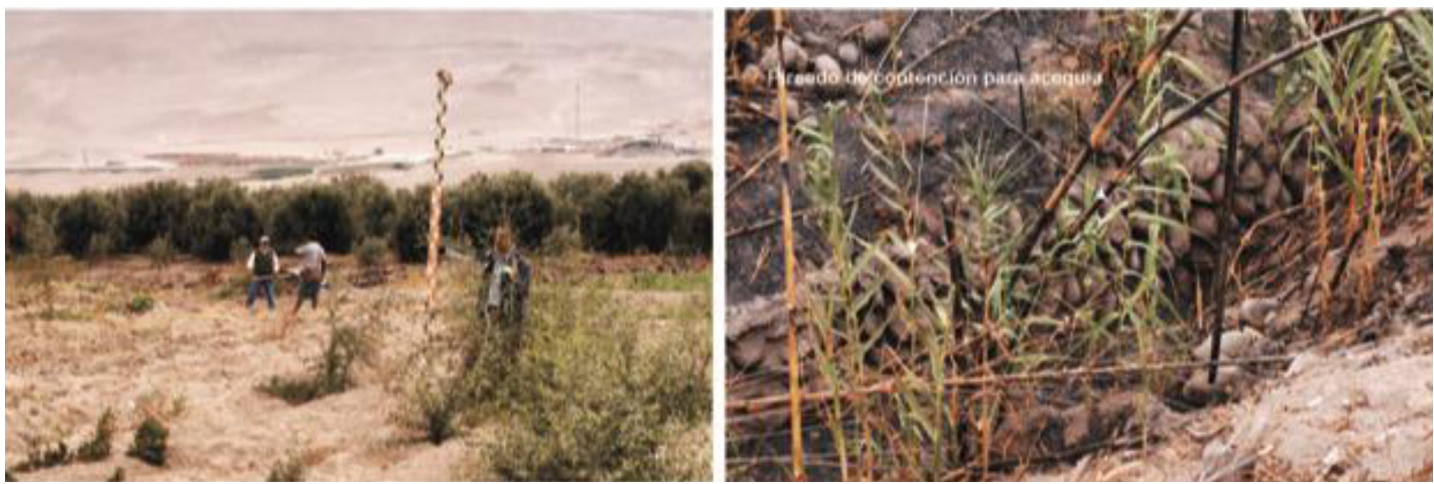

Figura 4. Manantial San Miguel.
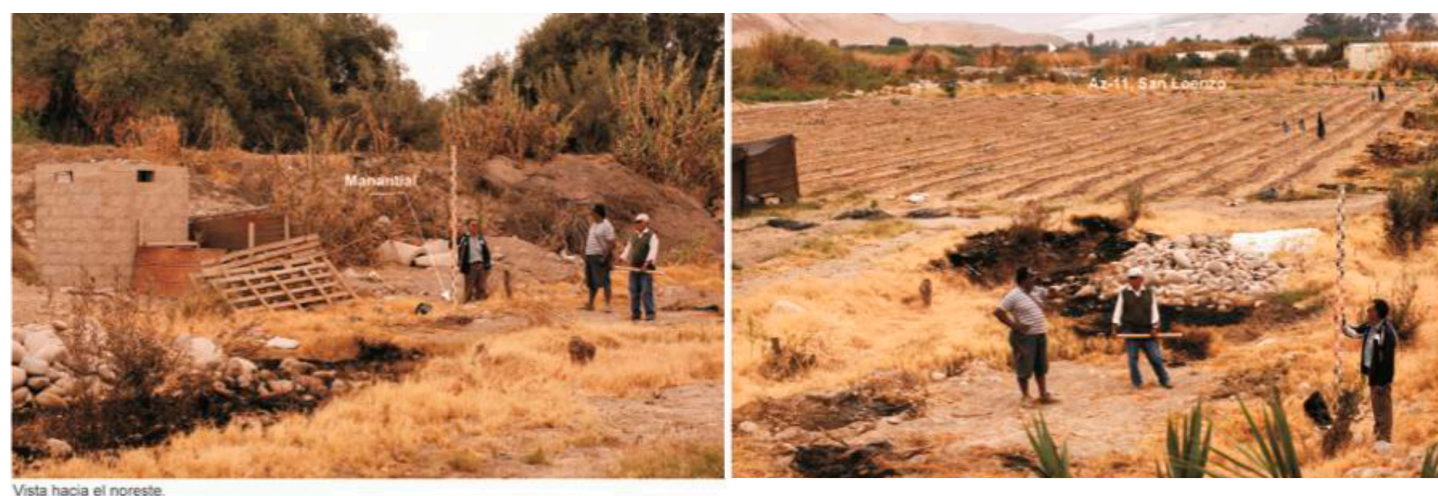

Figura 5. Manantial Matavaca. 

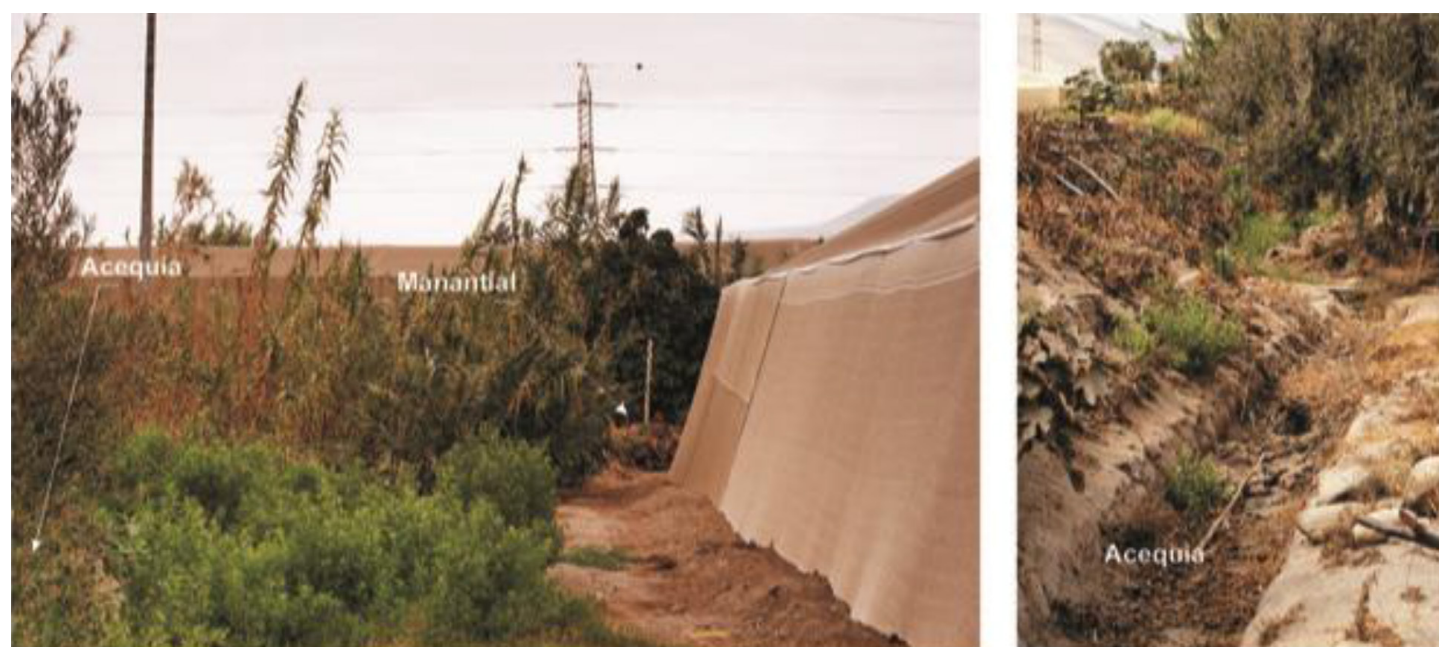

Figura 6. Manantial El Quinto.
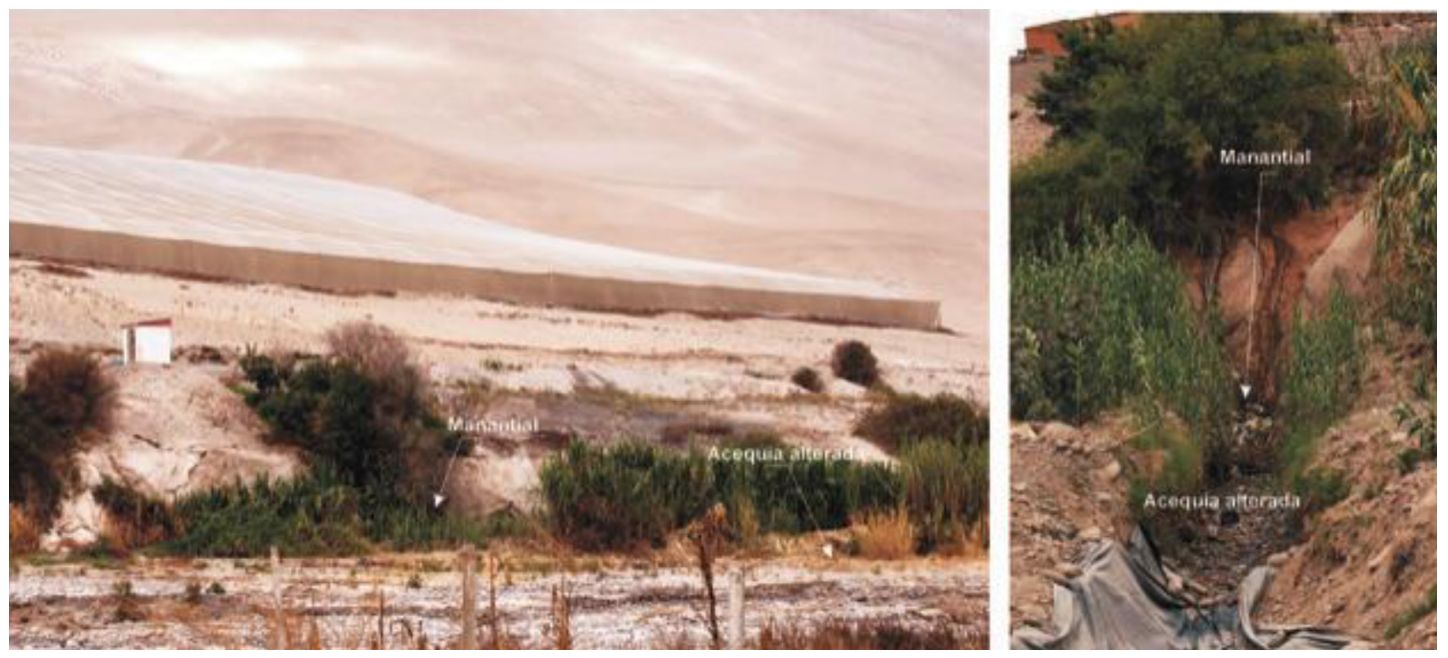

Figura 7.Manantial El Socavón, asociada a acequias. Familia Madrid.

período estival, alcanzando la superficie del terreno, y que permanecen por meses como espejos de agua. En el entorno natural próximo a cada afluente predominan tupidos cañaverales, totorales, árboles y pastizales (Ledezma, 2014). La adición de todos ellos con su entorno determina un amplio ecosistema denominado humedal (Tabla 1). Respecto a las características físicas de estos ojos de agua, presentan dimensiones que van de $1.80 \mathrm{~m}$ a $3.0 \mathrm{~m}$; tienen forma irregular y sus aguas son de coloración oscura como consecuencia de los sedimentos y acumulación de raíces, barro, musgo y basuras presentes en los alrededores de las vertientes. Las paredes son de conformación irregular con salientes y entradas de roca. Los suelos que rodean estos ojos de agua están constituidos por sedimentos barrosos.

\section{Discusión sobre las evidencias acuíferas}

En relación con su ubicación y por qué emergen estas aguas subterráneas, podemos señalar que a nivel de superficie, la dinámica geomorfológica de la quebrada El Diablo aporta la formación de una terraza de origen fluvial-aluvión que se adentra $500 \mathrm{~m}$ en el valle, testimoniada en un perfil de curso irregular. Por los sucesivos torrentes sedimentarios que con el tiempo le otorgaron 


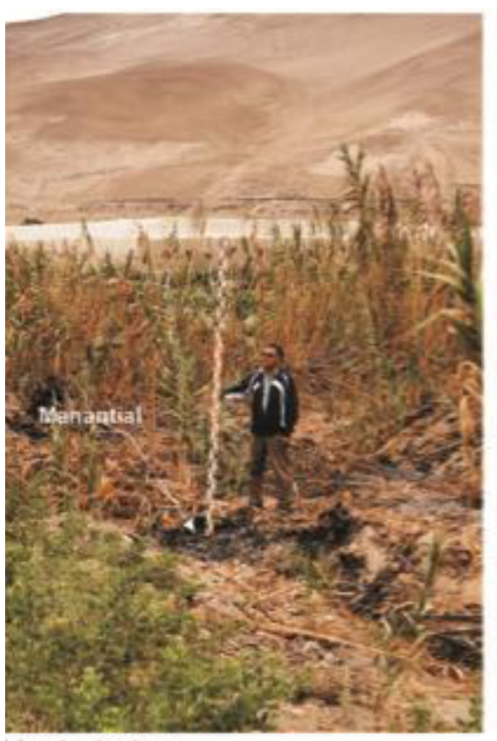

Vista hacia el sur.

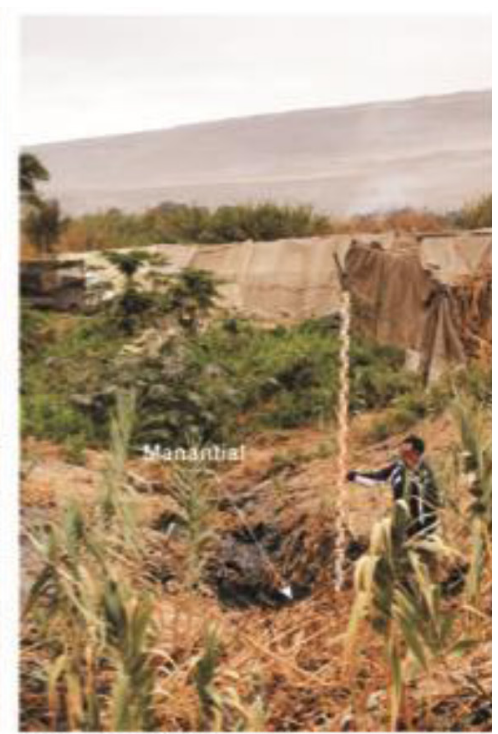

Vista hacia el norte

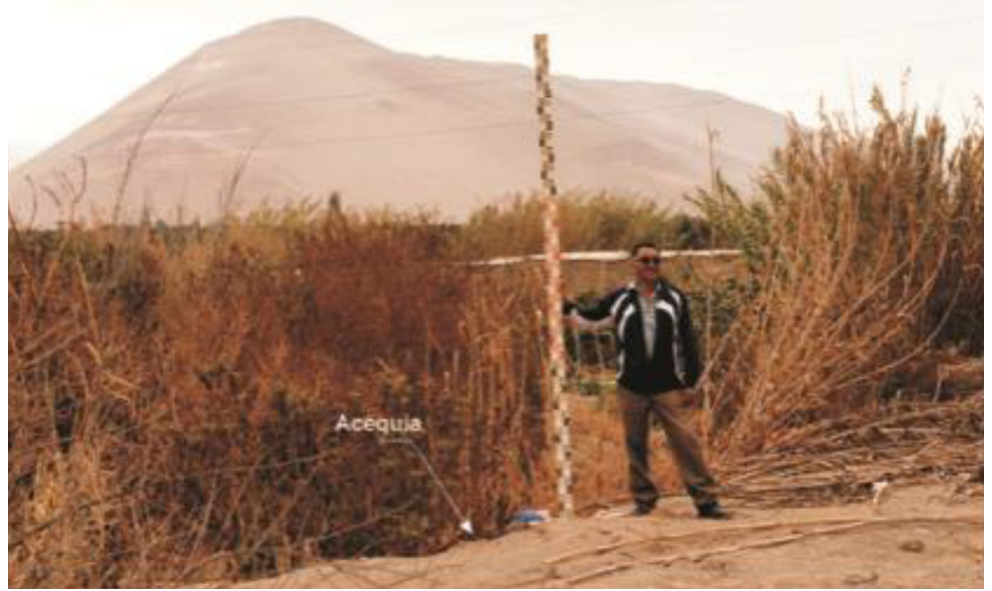

Figura 8. Manantial Hornito.

expansión horizontal y espesor, algunos manantiales pudieron haber sido sellados, o en caso contrario, las aguas subterráneas fueron impedidas de llegar a superficie, confluyeron en otros o emergieron en las inmediaciones.

En la medida que se avanza hacia el oeste, sector bajo del valle de Azapa, este espacio presenta un mayor ensanchamiento, un fondo constituido por depósitos aluviales, laderas pronunciadas, menor verticalidad que en los sectores interiores, presencia de pequeñas terrazas formadas por acumulación fluvial y aportes por la gravedad de materiales provenientes de las laderas. Estas terrazas fueron los espacios preferidos para asentarse por los agricultores prehispánicos, ya que se encuentran buenos suelos para la práctica de la agricultura, así como los afloramientos de aguas subterráneas de donde emergió agua dulce de buena calidad para el riego de frutas y hortalizas.

En cuanto a la captación de las aguas en directa relación con las vertientes Pejerrey, El Quinto, El Indio Muerto, La Noria 1 y 2, San Miguel y El Estanque, se detectaron segmentos de acequias que permitieron la captación y conductividad de aguas para acopios, reforzamientos para afluentes débiles e irrigación de suelos parcelados destinados a cultivos. El trazado sinuoso del surco es simple, 40 a $50 \mathrm{~cm}$ de profundidad y ancho similar, conservando el 


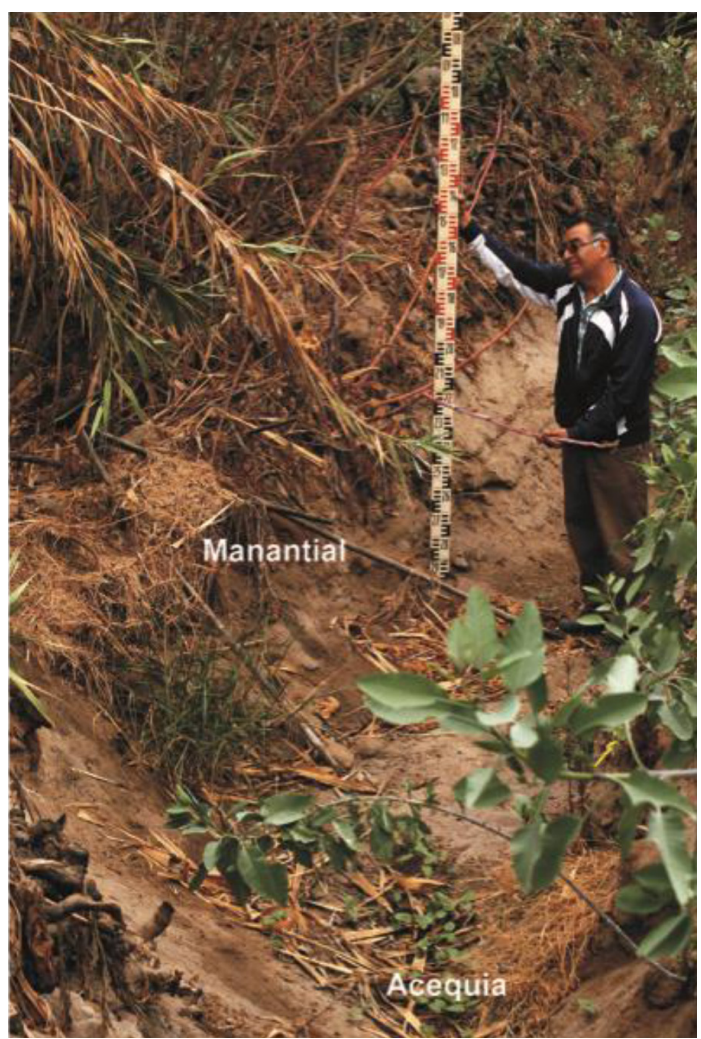

Figura 9. Manantial El Indio Muerto.

reforzamiento de ambos flancos con cantos rodados extraídos del río San José. Estos antecedentes, de igual manera, pueden ser la descripción de la realidad prehispana en la que las distintas estancias humanas paulatinamente comienzan a complejizarse en torno del desarrollo agrícola y atisbos de empleos en técnicas hidráulicas.

Con respecto a los sistemas de riego y plantaciones, correspondería al sistema denominado caracol, que consistía en hacer surcos en forma de $\mathrm{S}$ más bien en ángulos rectos, intercalados infinitamente de manera de producir una circulación expedita de las aguas. Este sistema fue observado por Frezier en la costa de Arica en 1713. Señaló que "una vez brotada la semilla $i$ en estado de transplantar, colocan las matitas como serpentenado, de modo que la disposición misma de las asequias de riego, llegue el agua con suavidad al pie de la planta, entones ponen alrededor de cada una tanto guano como cabe en el puño...". (Frezier, 1732: 152). Este sistema de traslado de agua racionaliza el recurso hídrico al máximo, entregando a la planta lo mínimo indispensable, a la vez que compatibiliza el surco poco profundo con la escasa calidad del suelo. Nos inclinamos a pensar que este fue el sistema de trabajo agrícola
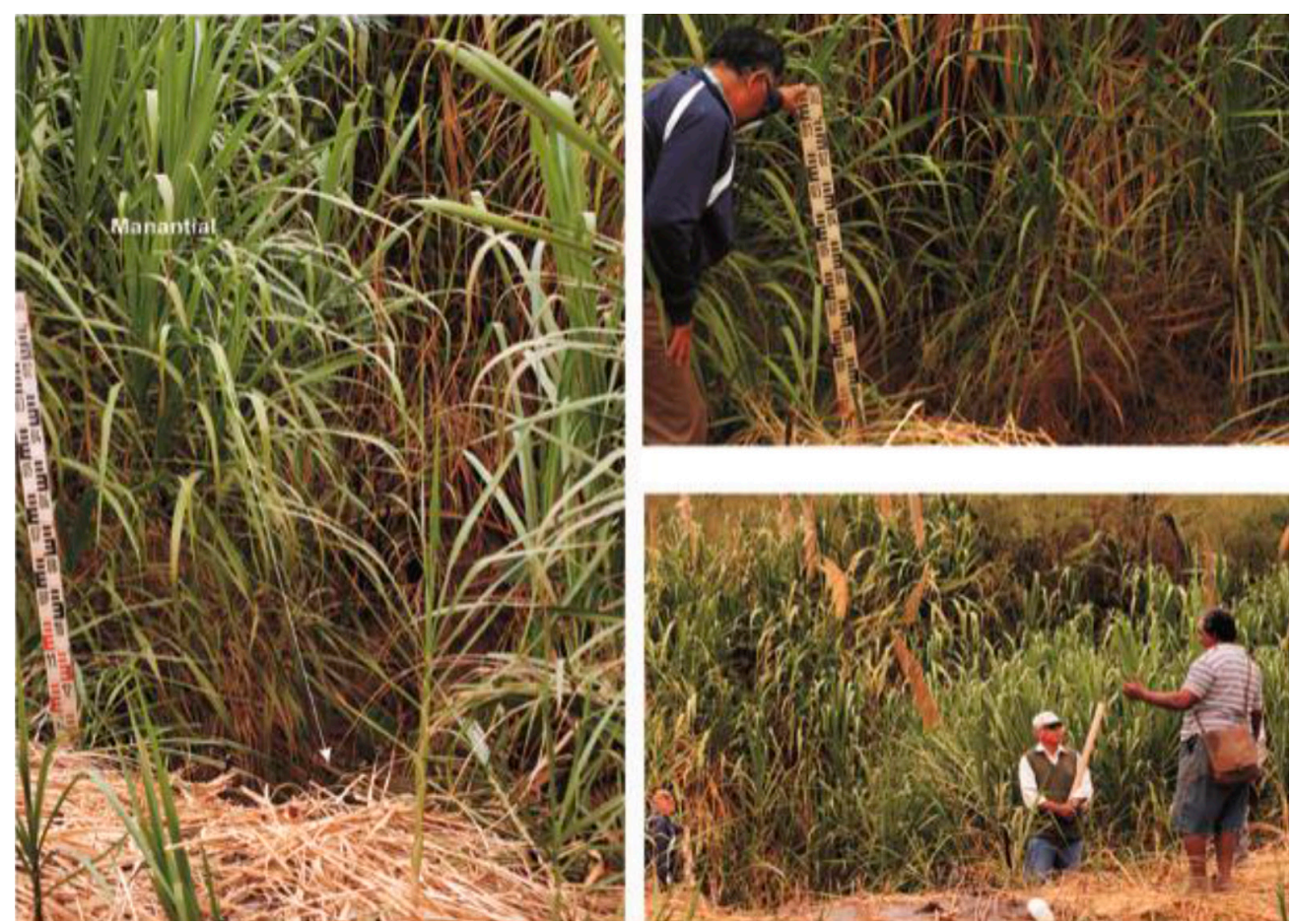

Figura 10. Manantial Conchalique. 

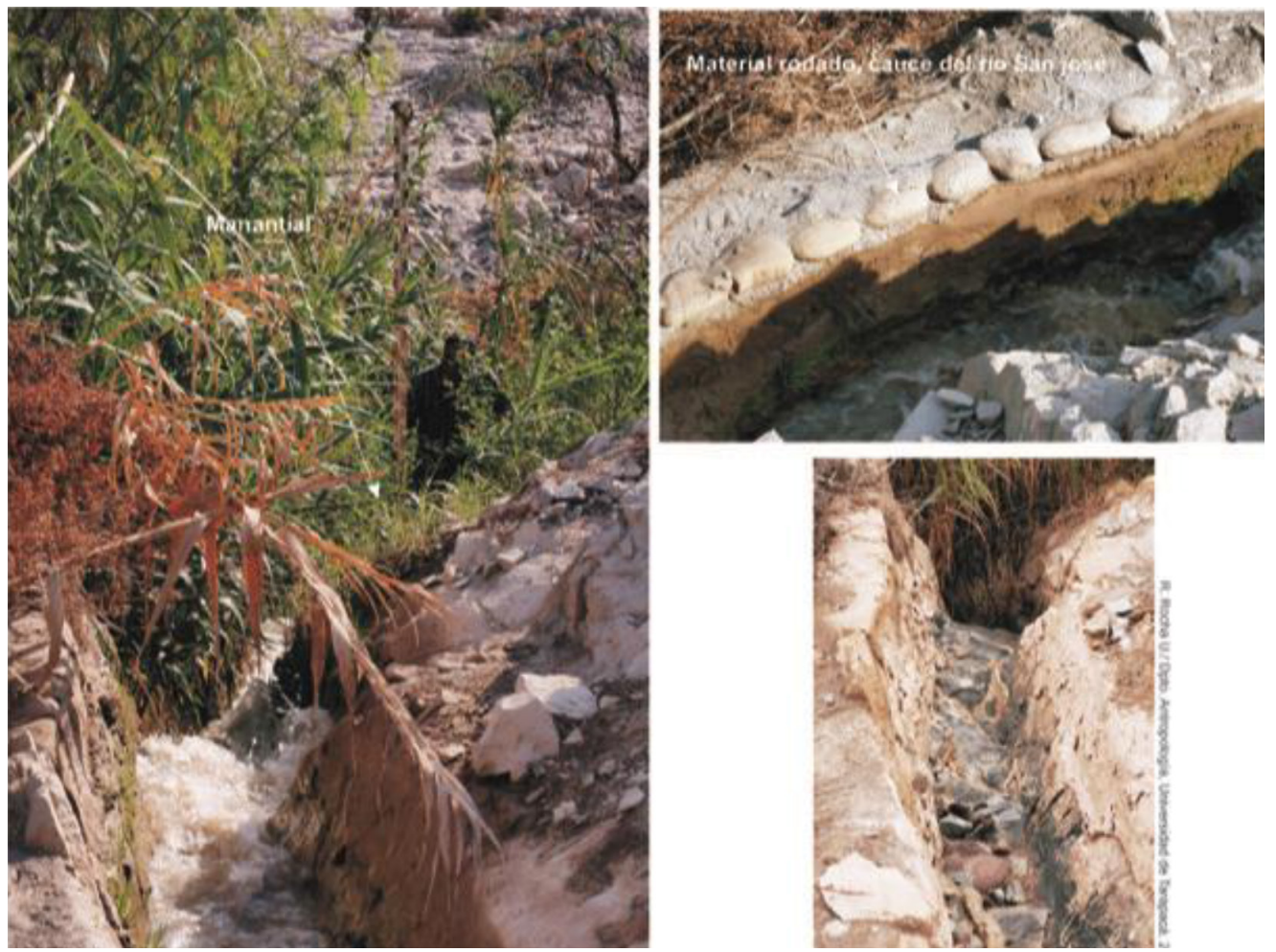

Figura 11. Manantial La Peña y acequias asociadas.
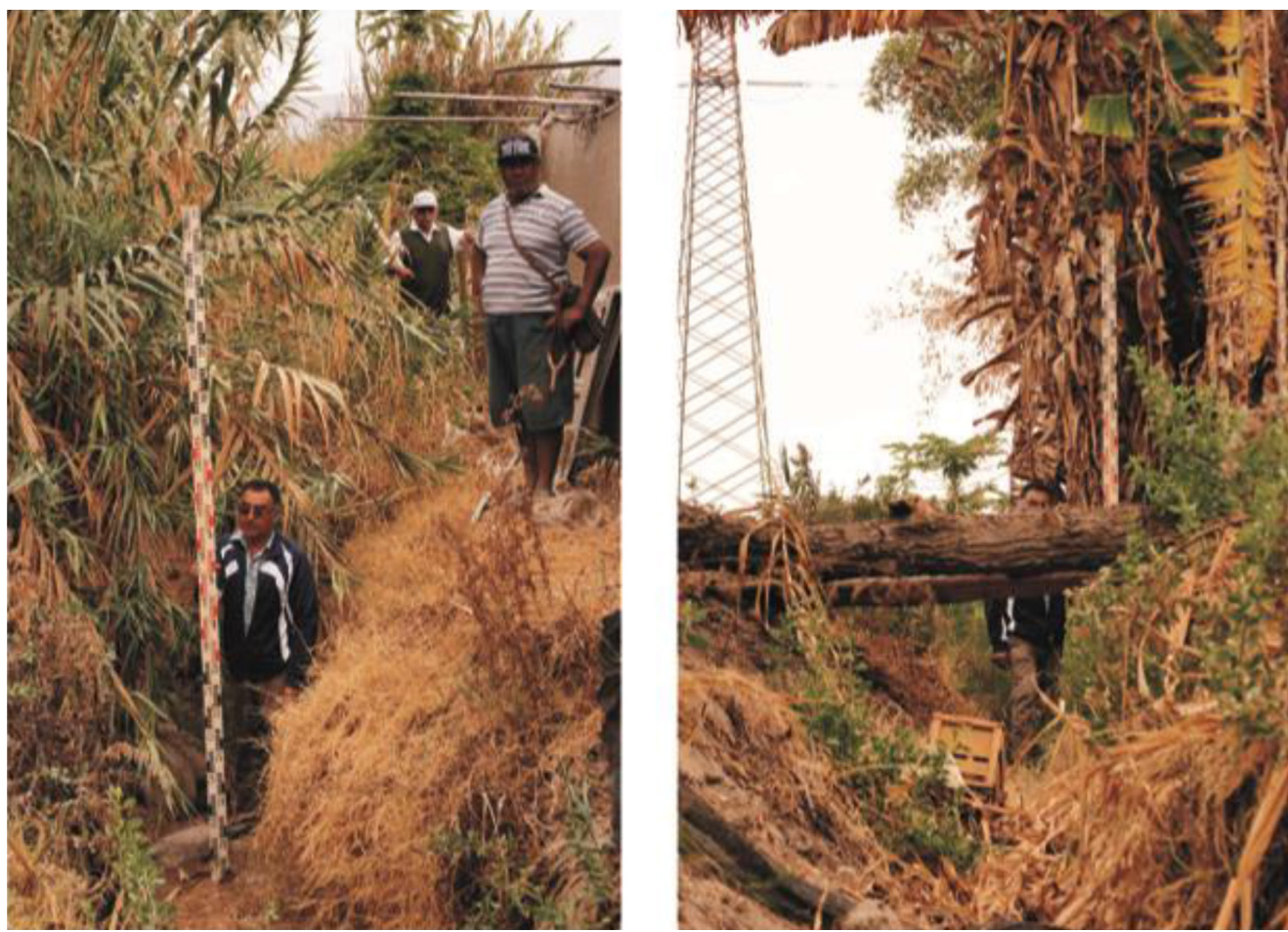

Figura 12. Manantial Pejerrey. Vistas hacia el este y oeste. 
Tabla 1. Resumen de vertientes área Quebrada del Diablo y San Lorenzo, sector medio Valle de Azapa.

\begin{tabular}{|c|c|c|c|c|c|}
\hline Vertiente & Ubicación & Propiedad & $\begin{array}{l}\text { Coordenadas } \\
\text { Geográficas }\end{array}$ & Vigencia & Observaciones \\
\hline Caniviri & $\begin{array}{l}\text { Sector Las Riberas, Km } 16.9 \\
\text { Flanco norte río San José. }\end{array}$ & $\begin{array}{l}\text { Parcela Sr. Juan Gutiérrez } \\
\text { Rol 3430-14 }\end{array}$ & $\begin{array}{l}19 \mathrm{~K} 379540.00 \\
\text { E } 7948992.00 \mathrm{~N}\end{array}$ & ¿Eventual? & No se aplica para regadío \\
\hline Peña Blanca & $\begin{array}{l}\text { Sector Las Riberas, Km } 15.24 \\
\text { Flanco norte río San José. }\end{array}$ & Sr. Amadeo Carbone & $\begin{array}{l}19 \mathrm{~K} 377993.00 \\
\text { E } 7949833.00 \mathrm{~N}\end{array}$ & ¿Eventual? & No se aplica para regadío \\
\hline La Concepción & $\begin{array}{l}\text { Sector Las Riberas, Km } 14.12 \\
\text { Flanco norte río San José }\end{array}$ & $\begin{array}{l}\text { Familia Silva (En } 1997 \text { perteneció } \\
\text { a Sr. Humberto Andía. Rol 3430- } \\
\text { 1. Asociada a parcela de Serafina } \\
\text { Lombardi Rol 3430-52) }\end{array}$ & $\begin{array}{l}19 \mathrm{~K} 377083.00 \\
\text { E } 7950456.00 \mathrm{~N}\end{array}$ & $\begin{array}{l}\text { Flujo } \\
\text { intermitente }\end{array}$ & $\begin{array}{l}\text { No se aplica para regadío. } \\
\text { Posible acequia para alimentar } \\
\text { acopios }\end{array}$ \\
\hline La Noria & $\begin{array}{l}\text { Sector San Miguel. Ribera } \\
\text { norte río San José, Km 13,66. } \\
\text { Información complementaria por } \\
\text { Sr. Pedro Madrid, Enero } 2015\end{array}$ & Sucesión Balmonte? & $\begin{array}{l}19 \mathrm{~K} 376710.00 \\
\text { E } 7950718.00 \mathrm{~N}\end{array}$ & ¿Eventual? & $\begin{array}{l}\text { No se aplica para regadío. Ace- } \\
\text { quias para alimentar acopios } \\
\text { Noria } 1 \text { y } 2 \text {. }\end{array}$ \\
\hline San Miguel & $\begin{array}{l}\text { Sector San Miguel. Ribera norte } \\
\text { río San José, Km 13,24 }\end{array}$ & $\begin{array}{l}\text { Entre parcelas de Lido Carbone } \\
\text { y Eda Carbone }\end{array}$ & $\begin{array}{l}19 \mathrm{~K} 376626.00 \\
\text { E } 7950926.00 \mathrm{~N}\end{array}$ & Eventual? & $\begin{array}{l}\text { No se aplica para regadío. } \\
\text { Recibía aporte hídrico desde } \\
\text { La Concepción para acopio } \\
\text { final en Cooperativa Juan Noé. }\end{array}$ \\
\hline Matavaca & $\begin{array}{l}\text { Sector San Miguel, km 13,24. } \\
\text { Ribera norte río San José. }\end{array}$ & Parcela rol $3420-40$ & $\begin{array}{l}19 \mathrm{~K} 376326.00 \mathrm{E} \\
7950723.00 \mathrm{~N}\end{array}$ & $\begin{array}{l}\text { Alterada por } \\
\text { nivelaciones } \\
\text { topográficas en } \\
\text { cauce de río. }\end{array}$ & Asociada a acequias. \\
\hline El Quinto & $\begin{array}{l}\text { Sector San Miguel, km } 12.78 \\
\text { Ribera norte, río San José. }\end{array}$ & $\begin{array}{l}\text { Entre parcelas: Sucesión } \\
\text { Baluarte rol 3420-45 y Aurelio } \\
\text { Noce. Rol 3420-35. }\end{array}$ & $\begin{array}{l}19 \mathrm{~K} 376039.00 \\
\text { E } 7951087.00 \mathrm{~N}\end{array}$ & $\begin{array}{l}\text { Flujo } \\
\text { intermitente }\end{array}$ & $\begin{array}{l}\text { No se aplica para regadío. Aso- } \\
\text { ciada a obras de pretiles en } \\
\text { 1960, JJAA. Sedimentación } \\
\text { por acopio extenso. }\end{array}$ \\
\hline El Socavón & $\begin{array}{l}\text { Sector San Miguel, km } 13.76 \\
\text { Ribera sur, río San José. }\end{array}$ & $\begin{array}{l}\text { Sr. Manuel Madrid, } \\
\text { rol 3430-79 }\end{array}$ & $\begin{array}{l}19 \mathrm{~K} \\
376654.90 \mathrm{E} \\
7950264.46 \mathrm{~N}\end{array}$ & $\begin{array}{l}\text { Flujo } \\
\text { permanente }\end{array}$ & $\begin{array}{l}\text { Fue utilizada para riego y aportó } \\
\text { aguas con Las Ánimas. Hoy no } \\
\text { se aplica para regadío. }\end{array}$ \\
\hline Las Ánimas & $\begin{array}{l}\text { Sector San Miguel, km } 13.24 \\
\text { Ribera sur, río San José. }\end{array}$ & Rol 3430-44 & $\begin{array}{l}19 \mathrm{~K} \\
376212.00 \\
\text { E 7950528.00 N }\end{array}$ & Eventual? & $\begin{array}{l}\text { Fue utilizada para riego. Hoy no } \\
\text { se aplica para regadío. }\end{array}$ \\
\hline Hornito & $\begin{array}{l}\text { Sector San Miguel, km } 12.96 \\
\text { Ribera sur, río San José. }\end{array}$ & Sr. Miguel Yampara & $\begin{array}{l}19 \mathrm{~K} \\
376047.00 \\
\text { E } 7950757.00 \mathrm{~N}\end{array}$ & ¿Eventual? & Hoy no se aplica para regadío. \\
\hline Pejerrey & $\begin{array}{l}\text { Sector San Miguel, km } 12.9 \\
\text { Ribera sur, río San José. }\end{array}$ & Sr. Miguel Yampara & $\begin{array}{l}19 \mathrm{~K} \\
376000.00 \\
\text { E } 7950796.00 \mathrm{~N}\end{array}$ & ¿Eventual? & $\begin{array}{l}\text { Fue utilizada para riego. Hoy no } \\
\text { se aplica para regadío. }\end{array}$ \\
\hline $\begin{array}{l}\text { El Indio } \\
\text { Muerto }\end{array}$ & $\begin{array}{l}\text { Sector San Miguel, km } 12.73 \\
\text { Ribera sur, río San José. }\end{array}$ & Sin información & $\begin{array}{l}19 \mathrm{~K} \\
375849.00 \\
\text { E 7950870.00 S }\end{array}$ & ¿Eventual? & $\begin{array}{l}\text { Posible uso en riego. Asociada } \\
\text { a acequias de Conchalique. }\end{array}$ \\
\hline Conchalique & $\begin{array}{l}\text { Sector San Miguel, km } 12.66 \\
\text { Ribera sur, río San José. }\end{array}$ & Sr. Pablo Benavides & $\begin{array}{l}19 \mathrm{~K} \\
375870.00 \\
\text { E 7950713.00 S }\end{array}$ & ¿Eventual? & $\begin{array}{l}\text { Profunda Posible uso en riego. } \\
\text { Asociada a acequias. }\end{array}$ \\
\hline La Peña & $\begin{array}{l}\text { Sector San Miguel, km } 11.59 \\
\text { Ribera sur, río San José. } \\
\text { Base noreste de reserva } \\
\text { arqueológica Az-11. }\end{array}$ & Sin información & $\begin{array}{l}19 \mathrm{~K} \\
375209.00 \\
\text { E } 7951549.00 \mathrm{~S}\end{array}$ & ¿Eventual? & Sin información \\
\hline
\end{tabular}


que operó en el valle en tiempos prehispánicos, puesto que no hemos hallado evidencias de otro sistema distinto como el de terrazas construidas en piedras tan común en los valles serranos del norte de Chile.

\section{Comentarios finales}

La existencia de complejos de manantiales aún vigentes como los descritos para el área Quebrada del Diablo-San Lorenzo está relacionada con la importante dinámica en la composición y comportamiento geológico del subsuelo, que permite la emergencia de aguas subterráneas a través de ojos de agua. Si bien la tierra les permitió una variedad de cultivos, la mayor producción agrícola en el poblado de San Lorenzo estuvo centrada en los cultivos de maíz, frijoles, ají, camotes, yuca y calabazas, además de frutos de árboles como pacae, chañar, algarrobos. Los restos aparecen reiteradamente en las basuras de las viviendas, ofrendas en tumbas y en los desechos de producción que fue depositada en los pozos de almacenaje de dicho asentamiento. Para que existiera esta productividad agrícola, pensamos que tuvo que haber habido un recurso hídrico permanente, lo que hizo que la población controlara el uso del agua asegurando el riego para los cultivos. La explotación de las vertientes en el sector medio del valle y el traslado del agua por acequias para regar las melgas que se situaron en los alrededores del poblado de San Lorenzo constituyeron la base sobre la cual se montó la explotación agraria, la que habría contribuido a un mayor crecimiento de la población del valle (Figura 13).

En lo que respecta a la captación de los recursos, se ha determinado para el sector medio del valle dos diámetros de explotación de las vertientes. El primero correspondería al grupo de 14 vertientes reconocidas en la prospección, las cuales se hallan espacialmente relacionadas con el poblado (Pukara) de San Lorenzo. En este asentamiento es posible que se hayan asentado un gran número de agricultores del valle, lo cual hizo que el lugar (cerros de San Lorenzo) se convirtiera en el mayor centro de intercambio económico de

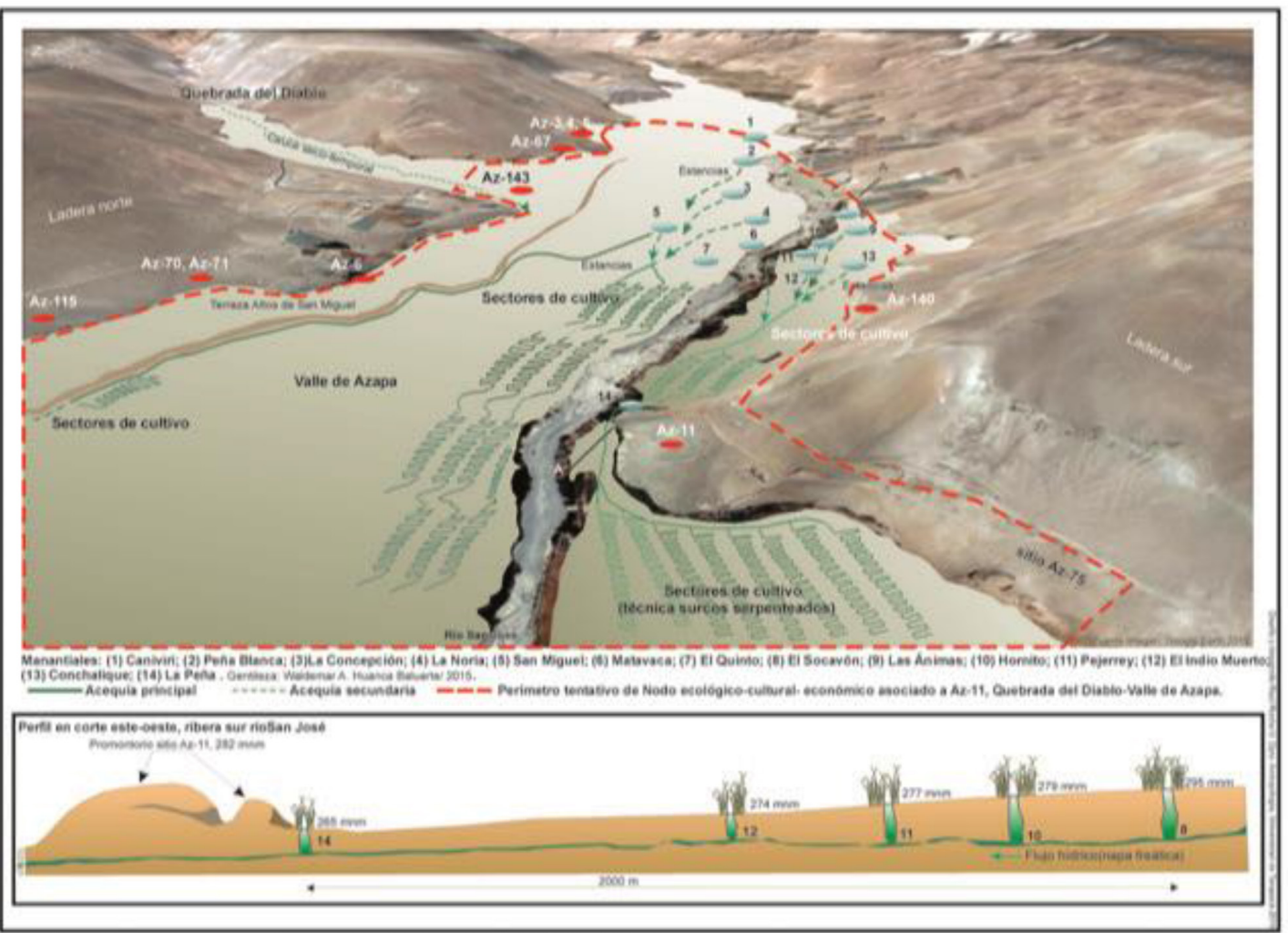

Figura 13. Propuesta hipotética para irrigación de áreas de cultivos desde manantiales. 
la zona con productos que llegaron de distintas regiones de los Andes Centro-Sur. Un segundo radio de explotación de vertientes ejecutado por los agricultores de San Lorenzo correspondió a El Gallito, Media Luna, Las Ánimas y Mita Chica. Ambos grupos de vertientes poseen aguas de buena calidad, aptas para el consumo humano y riego de frutales y hortalizas.

\section{Agradecimientos}

Este artículo es producto de la investigación desarrollada en el proyecto UTA 3736-18. Se agradece la información entregada por los Srs. Valdemar Antonio Huanca, José Linares y Ricardo Mendoza en torno a los recursos de agua de vertiente en el valle de Azapa.

\section{Literatura Citada}

Crom, W.

1988-1989. La interpretación geográfica de fuentes históricas: el ejemplo del valle de Azapa, Arica-Chile. Diálogo Andino, 7/8: 43-56.

Frezier, A.

1908. Relación de viaje a las costas de Chile y Perú (1716), (1732). Traducido por Nicolás Peña. Imprenta Mejía. Santiago, Chile. 202 p.

Greisal, R.

1974 La colección botánica del Centro de Investigación y Capacitación Agrícola (CICA). Revista. Idesia 3. 185-195. INGENDESA.

2003. Estudio de factibilidad de embalses para los valles de Lluta y Azapa. Resumen Ejecutivo. Santiago, Chile. 31 p.

Keller, C.

1946. El Departamento de Arica. Editorial Zig-Zag, Santiago, Chile. 334 p.

Ledezma M.

2014. Área de captación de recursos vegetales para la construcción del túmulo 1-sitio Az-67, valle de Azapa,
Arica-Chile. En: Muñoz; I.; Fernández, S. (Eds.). Mil Años de Historia de los Constructores de Túmulos de los Valles Desérticos de Arica: Paisaje, Monumentos y Memoria. Ediciones Universidad de Tarapacá. Arica, Chile. pp. 213-228.

Muñoz, I.

2004. Estrategias de Organización Prehispánicas en Azapa: el Impacto de la Agricultura en un Valle del Desierto Costero del Pacífico. Ediciones Universidad de Tarapacá. Arica, Chile. 357 p.

Tapia, A.

2014. Marco geográfico natural del valle de Azapa. En Mil Años de Historia de los Constructores de Túmulos de los Valles Desérticos de Arica: Paisaje, Monumentos y Memoria. I. Muñoz; S. Fernández (Eds.). Ediciones Universidad de Tarapacá. Arica, Chile. Pp. 23-38.

Vázquez de Espinosa, A.

1948 [1618]. Compendio y Descripción de las Indias Occidentales. Smithsonian Institution. Washington, D.C., U.S. 801 p. 